\title{
UM MODELO ANACRÔNICO PARA OS CURSOS DE LICENCIATURA NO BRASIL: UMA ANÁLISE DO PARECER $\mathrm{CNE} / \mathrm{CP} \mathrm{N}^{\circ} 22 / 2019$
}

\author{
Un modelo anacrónico para los cursos de licenciatura en Brasil: \\ Análisis del dictamen $\mathrm{CNE} / \mathrm{CP} n^{\circ} 22 / 2019$ \\ An anachronic model for Teacher Degree courses in Brazil: \\ an analysis of the Report CNE/CP $n^{\circ} 22 / 2019$
}

Camila Lima Coimbra*

https://doi.org/10.38117/2675-181X.formov2020.v2i2n4.621-645

\section{RESUMO}

Este artigo tem como objetivo trazer ao debate, a formação de professores/as para a Educação Básica, a partir de uma análise crítica do Parecer CNE/CP n 22/2019. São interpretações dialéticas de unidades temáticas que podem materializar o delineamento do perfil de professores/as para o Brasil, desdobrados posteriormente, na aprovação da Resolução CNE/CP n ${ }^{\circ}$ 02/2019. Quais perspectivas são apresentadas por esse marco legal, para a formação de professores/as no Brasil? Esta é a problematização deste artigo. Para isso, analisa-se o Parecer que tem os referenciais que deveriam sustentar as proposições da Resolução. Nesse sentido, compreende-se como fundamental esta análise pormenorizada, levantando os pontos que justificam a denominação deste, como um modelo anacrônico para a formação de professores/as da Educação Básica.

PALAVRAS CHAVE: Educação Básica; Formação de professores; Diretrizes curriculares.

\section{RESUMEN}

Este artículo tiene como objetivo llevar al debate, la formación de los profesores para la Educación Básica, a partir de un análisis crítico del Dictamen No 22/2019 de la $\mathrm{CNE} / \mathrm{CP}$. Son interpretaciones dialécticas de unidades temáticas que pueden materializar el diseño del perfil del maestro para Brasil, más tarde desplegada, en la aprobación de la Resolución CNE/CP No 02/2019. ¿Qué perspectivas presenta este marco legal para la educación de maestros en Brasil? Esta es la problemática de este artículo. Para ello, analiza las conclusiones que tienen las referencias que deben apoyar las propuestas de la Resolución. En este sentido, este análisis 
detallado se entiende como fundamental, planteando los puntos que justifican su denominación, como modelo anacrónico para la formación de los profesores de Educación Básica

PALABRAS CLAVE: Educación Básica; Formación del profesorado; Directrices Curriculares.

\begin{abstract}
This article aims to bring to the debate issues on teacher education for Basic Education, based on a critical analysis of Report CNE / CP n ${ }^{\circ}$. 22/2019. They are dialectical interpretations of thematic units that can materialize the outline of the profile of teachers for Brazil, unfolded later, in the approval of Resolution CNE / $\mathrm{CP} \mathrm{n}^{\circ}$. 02/2019. What perspectives are presented by this legal framework for teacher education in Brazil? This is the problematization of this paper. For this, we analyze the Report that should support the propositions of the Resolution. This detailed analysis is fundamental, raising the points that justify its name, as an anachronistic model for teacher education of Basic Education.
\end{abstract}

KEYWORDS: Basic Education; Teacher education; Curriculum Guidelines.

\title{
Contexto: quais modelos? Para qual projeto de sociedade?
}

\author{
"Aonde fica a saída?" \\ perguntou Alice ao gato que ria. \\ "Depende" \\ respondeu o gato. \\ "De quê?" \\ replicou Alice. \\ "Depende de para onde você quer ir..." \\ Lewis Carol
}

Começo este texto com a frase célebre do gato em Alice no País das Maravilhas, de Lewis Carol, para insistir que, no campo educacional, o caminho a seguir depende de onde queremos ir. Assim, as concepções que nos constituem traduzem as nossas escolhas, tanto no campo educacional quanto no campo político. Qual decisão tomar? Como articular um projeto de formação nacional que dê conta dos atuais desafios educacionais? Qual a relação entre o projeto formativo e os princípios que defendemos historicamente? Estamos aqui nos referindo à formação do/a professor/a da Educação Básica, realizado no Brasil, por meio de cursos de licenciatura, nas Instituições de Ensino Superior do país, 
- lugar historicamente construído para essa formação. Qual modelo de formação de professores/as para o momento atual? Para qual projeto de sociedade? São muitas as questões postas para a formação de professores no Brasil. Para respondê-las, e de que forma, é importante saber aonde se quer chegar e como.

Ao iniciar esse debate sobre a formação de professores, partimos da compreensão de que formação implica profissão e esta implica valorização. São três dimensões, em nossa realidade, fundamentais para referenciar o ponto de partida para as análises que seguem sobre a formação de professores. A formação, assim, é compreendida como lugar de vida e morada do/a professor/a, em que sua existência profissional, permanentemente, acompanhada por processos formativos, sejam eles de início, meio ou fim da carreira. Assim, é possível e necessário admitir o grau de importância que a formação carrega para o profissional. A luta histórica do movimento dos educadores em defesa da formação é a luta pela valorização da profissão. O que temos construído como representação social da docência, em uma perspectiva ampliada, recebe as consequências das legislações pertinentes que muitas vezes, se aproximam das lutas históricas, no sentido da valorização profissional do magistério, e outras vezes, se distanciam. (BRZEZINSKI, 1996; ANFOPE, 1998)

A formação de professores/as para a Educação Básica no Brasil, tem um histórico interessante, amplamente investigado por diversos autores. A temática foi discutida em outro artigo em que definimos três modelos de formação de professores/as no Brasil (COIMBRA, 2020). Apesar de recente, à época da redação, ainda não estava em discussão a Resolução $\mathrm{CNE} / \mathrm{CP} \mathrm{n}^{\circ} 2 / 2019^{1}$, por isso, este artigo tem, também, como finalidade investir na análise deste marco legal e as mudanças significativas que trouxeram para a formação de professores/as no Brasil.

Para análise deste modelo atual, faz-se necessário contextualizar os três momentos, delineados por Coimbra (2020), a partir da análise dos contextos históricos, políticos, sociais, culturais e econômicos da constituição dos modelos de formação brasileiros.

Entendemos que coabitam os três modelos de formação no cenário brasileiro. O modelo conteudista (1939-...), com maior tempo cronológico e, portanto, bastante enraizado nas concepções e práticas docentes atuais; o modelo de transição (2002-...), que rompe com a lógica da supremacia do conteúdo, incorporando as práticas como componentes curriculares; e, por fim, o modelo de resistência (2015...), que amplia a carga horária, mantém as práticas como componentes

\footnotetext{
${ }^{1}$ Foi surpreendente a rapidez do processo que levou a aprovação da Resolução CNE/CP no 02/2019: o documento referência foi publicizado às vésperas da única audiência pública, realizada em 08/10/2019, e sem considerar as críticas das entidades nacionais, em 07/11/2019, a Resolução foi aprovada.
} 
curriculares, permanece com a integralidade da formação e incorpora a valorização profissional em seu teor. (COIMBRA, 2020, p.17)

Um quarto modelo foi inaugurado em 20 de dezembro de 2019, com a Resolução CNE/CP n²/2019 que define as Diretrizes Curriculares Nacionais para a Formação Inicial de Professores para a Educação Básica e institui a Base Nacional Comum para a Formação Inicial de Professores da Educação Básica (BNC-Formação), apenas publicada no Diário Oficial da União em 20 de fevereiro de 2020. Apesar do pouco tempo de sua publicação, entendemos ser um exercício de coragem analisar esta Resolução e sua proposição. Por isso, a importância de resgatar os modelos de formação existentes: a) modelo conteudista, criado em 1939, pelo Decreto $\mathrm{n}^{\circ} 1190$; b) modelo de transição, instituído a partir de 2002, com a Resolução CNE/CP n ${ }^{\circ} 1 / 2002$; c) o modelo de resistência, reiterado, ampliado e incorporado às lutas históricas, em 2015, por meio da Resolução CNE/CP nº 02/2015; e por fim, d) o modelo anacrônico, de 2019, instituído pela Resolução CNE/CP nº2/2019.

O modelo anacrônico, foi assim denominado por trazer, na análise desta autora, uma interpretação de que há, em seu interior, uma inversão da ordem do tempo. Ou seja, parece que essa legislação nega/erra a trajetória histórica que percorremos na construção de um perfil nacional para a formação de professores/as da Educação Básica, desde o movimento de abertura política no Brasil. A Resolução CNE/CP nº 02/2019 utiliza os conceitos e ideias de uma época passada para formar sujeitos de outro tempo histórico, com referências em outras realidades que não a nossa.

Por definição, "o anacronismo é uma forma equivocada onde tentamos avaliar um determinado tempo histórico à luz de valores que não pertencem a esse mesmo tempo histórico"2. Ou seja, um modelo anacrônico, fora de seu tempo, com a perspectiva de demonstrar como "somos os filhos da época, e a época é política", como poetiza Wislawa Szymborska ${ }^{3}$, nos ajudando a elucidar a categoria 'politicidade' presente no pensamento freireano e que tornou-se premissa para a análise deste artigo.

Em contraposição, a Resolução CNE/CP n ${ }^{\circ}$ 02/2015, em síntese, nosso modelo de resistência, expressava a incorporação de um movimento para a conquista de lutas históricas na formação de professores/as. Nesta resolução havia uma expressão clara do conceito de docência em sua complexidade, indicando a importância de um processo pedagógico comprometido com valores éticos, políticos e estéticos, e, especialmente, na compreensão de que a docência se materializa nessa práxis, na busca coerente entre o que pensamos e o que fazemos. Ou seja, a Resolução 02/2015 entende a

\footnotetext{
${ }^{2}$ Fonte: https://brasilescola.uol.com.br/historia/anacronismo.htm

${ }^{3}$ Wislawa Szymborska3 (1923-2012), poeta polonesa que recebeu o Prêmio Nobel de literatura em 1996.
} 
docência como ação educativa e como processo pedagógico intencional e metódico, envolvendo conhecimentos específicos, interdisciplinares e pedagógicos, conceitos, princípios e objetivos da formação que se desenvolvem entre conhecimentos científicos e culturais, nos valores éticos, políticos e estéticos inerentes ao ensinar e aprender, na socialização e construção de conhecimentos, no diálogo constante entre diferentes visões de mundo (BRASIL, 2015, p. 3, grifo nosso).

Ao compreender a docência desta forma, amplia-se a definição da profissão de professor/a, como um processo pedagógico intencional e metódico, que envolve várias dimensões humanas, por meio do diálogo. Assim, define-se um/a profissional adequado à nossa época, ao nosso tempo. Na busca da coerência teórica, o que propicia a existência de um curso de formação é a sua intencionalidade que materializa quais as concepções, finalidades e princípios de formação são pretendidos, expressos por meio de projetos pedagógicos das Instituições de Educação Superior. Assim, este conceito amplo de docência é um ponto de partida fundamental, pois, até então, ainda trabalhávamos com o termo regência, cunhado por meio da Lei de Diretrizes e Bases de 1971 (Lei nº 5692/71) que não conseguiria mais definir a complexidade, integralidade e características da docência neste tempo atual.

Essa definição assume a profissionalização da docência, e nos permite avançar na ideia de que a docência não pode ser considerada missão, vocação ou qualquer outro termo que a distancie da profissionalização. A ideia de assumir a docência com a intuição, o amor e o prazer em "dar aula" não define mais esta ação profissional, pois a complexidade da sua definição materializa a necessidade dos cursos de formação inicial e continuada para este exercício profissional. Tínhamos, assim, em uma legislação, uma definição que territorializa o espaço e o tempo da docência, por isso a necessidade de partir dela.

Em outra direção, ou seja, na contramão, a Resolução CNE/CP n ${ }^{\circ}$ 02/2019 não define o conceito de docência do qual parte, mas já declara o caminho a seguir (diria Alice, sabe onde quer chegar.):
A formação docente pressupõe o desenvolvimento, pelo licenciando, das competências gerais previstas na BNCC-Educação Básica, bem como das aprendizagens essenciais a serem garantidas aos estudantes, quanto aos aspectos intelectual, físico, cultural, social e emocional de sua formação, tendo como perspectiva o desenvolvimento pleno das pessoas, visando à Educação Integral. (BRASIL, 2019, p. 2 , grifo nosso)

Retoma-se a ideia da Alice, dizer o caminho sem dizer por que esta escolha e não outra. Evidencia-se que a "grande tarefa" desta Resolução é a de reduzir a formação de 
professores/as e colocá-la à serviço de uma formação neotecnicista para "a necessária aplicação" da BNCC - Base Nacional Comum Curricular. Assim, questionamos: Como visar uma formação integral de estudantes, se na formação de professores/as não compreendemos o/a profissional em uma visão integral? O que seria a Educação Integral nos termos desta legislação? Perguntas sem respostas, por enquanto...

Para Silva (2018),

o neotecnicismo pedagógico se faz presente nas atuais políticas educacionais, a partir de dois eixos centrais: (1) o reducionismo tecnicista - em que a formação de professores parte da dimensão acadêmica para a dimensão experimental/instrumental/pragmática e coloca a ênfase nas competências e habilidades dos professores e alunos para atingirem as metas e os resultados pré-estabelecidos (...) (SILVA, 2018, p. 11, grifo nosso)

Com pesar, identificamos que a Resolução de 2019, apresenta características que contradizem um caminho percorrido na consolidação de um perfil de formação de professores/as no Brasil, desde o final da década de 70, com a abertura política, após o Golpe Militar ${ }^{4}$ de 1964. A elaboração dessa Resolução, não considera essa história, e parece querer afirmar que a constituição desse perfil de formação de professores/as surge com a BNCC e a partir dela, todas as outras legislações precisam de atualização visando a sua aplicação. Partindo dessa premissa, vamos apontar os argumentos/características que sustentam o texto da Resolução em seu Parecer, para explicar por que denominamos este quarto modelo brasileiro, instaurado pela Resolução 2019, de modelo anacrônico, porque não o consideramos adequado ao nosso tempo, a nossa história e as nossas necessidades.

Desde 2017, com a aprovação da Resolução CNE/CP n 2, de 22 de dezembro de 2017, que instituiu a Base Nacional Comum Curricular da Educação Infantil e do Ensino Fundamental - BNCC 5 , o Ministério da Educação vem assumindo, por meio de vários ações, a proposição de Novas Diretrizes para a formação de professores, alegando a "necessária aplicação" da BNCC. Tal feito aguça a nossa inquietação pois, a concepção construída historicamente, para a docência, não a reduz a uma mera aplicação de currículos ou conteúdos ou objetos das áreas de conhecimento.

De acordo com o Parecer CNE/CP n 22/2019:

\footnotetext{
4 Denominamos de Golpe Militar, de acordo com as referências e a compreensão histórica que compartilhamos. Sugerimos como leitura: FERREIRA, Jorge e GOMES, Angela de Castro. 1964. O Golpe que Derrubou um Presidente e Instituiu a Ditadura no Brasil.

${ }^{5}$ Em 04 de dezembro de 2018, o CNE aprovou a BNNC do Ensino Médio, homologada em 14/12/2018, integralizando assim a BNCC da Educação Básica.
} 
A BNCC inaugura uma nova era da Educação Básica em nosso país. Pela primeira vez na história, logrou-se construir, no Brasil, um consenso nacional sobre as aprendizagens essenciais, que são consideradas como direito de todos e, portanto, devem ser, ao longo de todas as etapas e modalidades, asseguradas na Educação Básica. (BRASIL, 2019, p.1)

Qual seria a "nova era" inaugurada? Cabe observar que essas políticas educacionais foram homologadas em dezembro ${ }^{6}$, próximo ao início das férias escolares e recesso das Universidades Públicas brasileiras. Ao afirmar que pela primeira vez se conseguiu um consenso nacional sobre essa matéria, o CNE assume desconhecer a história, e desconsiderar tanto as críticas encaminhadas quanto a quantidade de Notas públicas $^{7}$ feitas em contrário a aprovação de tal modelo de formação e das críticas encaminhadas. (COIMBRA, 2020; ANFOPE, FORUMDIR, ANPED et al, 2019)

O texto continua:

Como consequência, este egrégio $\mathrm{CNE}$ entendeu que a regulação da formação docente, com base na Resolução CNE/CP $n^{\circ} 1 / 2006$ e na Resolução CNE/CP no 2/2015, precisava ser revista e atualizada de acordo com as recentes mudanças normativas. Além disso, o CNE entendeu, em tratativas com o MEC, que deveria também elaborar os referenciais que constituem a formação de professores para a implantação da BNCC em todas as etapas e modalidades da Educação Básica. (...) a Comissão Bicameral realizou uma série de reuniões com diferentes setores da Educação brasileira, tendo como ápice desse processo a Audiência Pública, realizada em 8 de outubro de 2019, com o objetivo de apresentar e discutir a proposta de reformulação da Resolução CNE/CP $n^{\circ}$ 2/2015, bem como colher subsídios para a deliberação da matéria pelo Colegiado. (BRASIL, 2019, p. 2, grifo nosso)

Da forma como aparece descrito, questionamos como a "série de reuniões" ocorreram? Com quais pares? Quais foram os interlocutores do MEC e do CNE? Qual o diálogo com as Universidades públicas? Assumimos esta pergunta porque entendemos que este seja o espaço de atuação e de pesquisa sobre a formação de professores/a no país 8 .

\footnotetext{
${ }^{6}$ A BNCC da Educação Infantil e Ensino Fundamental, aprovada em 15/12/2017 e homologada em 20/12/2017; a BNCC do Ensino Médio, aprovada pelo CNE em 04/12/2018 foi homologada pelo MEC em 14/12/2018 e a Res.02/2019, aprovada em 7/11/2019 foi homologada pelo MEC em 20/12/2019.

${ }^{7}$ Elaboradas e assinadas pela ANFOPE, ANPED, ANPAE, ABdC, entre outras entidades nacionais que se opuseram ao processo de elaboração, discussão e aprovação da BNCC, e a aprovação da Resolução 02/2019.

${ }^{8}$ Sugiro a leitura do Documento do Fórum de Licenciaturas da Universidade Federal de Uberlândia, após participação de representantes nesta Audiência.
} 
Assim, com este breve histórico e algumas definições importantes, consideramos o preâmbulo para nossa análise que acontece da seguinte forma: criamos algumas categorias frente a organização do próprio documento, do Parecer CNE/CP no 22/2019, elencando alguns pontos em destaque para a compreensão e crítica deste modelo anacrônico, instaurado pela Resolução CNE/CP n²/2019.

\section{Descrição do Parecer}

Todas as coisas - minhas, tuas, nossas, coisas de cada dia, de cada noite são coisas políticas.

Wisława Szymborska

Em linhas gerais, o Parecer CNE/CP n 22/2019 foi elaborado por Comissão composta pelos conselheiros: Maria Helena Guimarães de Castro (Presidente), Mozart Neves Ramos (Relator), Aléssio Costa Lima, Antonio de Araujo Freitas Júnior, Antonio Carbonari Netto, Aurina Oliveira Santana, Francisco César de Sá Barreto, Ivan Cláudio Pereira Siqueira, Luiz Roberto Liza Curi, Nilma Santos Fontanive e Suely Melo de Castro Menezes, e aprovado em 07 de novembro de $2019^{9}$.

O Parecer tem 51 páginas, inclusive com a proposição da Resolução. Constitui-se das seguintes partes: uma introdução com o histórico legal; um breve histórico das políticas de formação e valorização do professor; alguns indicadores de aprendizagem e da formação de professores, apontando o desafio do baixo valor social da carreira do magistério no Brasil; alguns referenciais e diretrizes internacionais; uma descrição sobre a Base Nacional Comum Curricular - BNCC; um item sobre a formação inicial do magistério da Educação Básica em nível superior, com os princípios da política da formação docente; princípios da organização curricular dos cursos de formação inicial; competências profissionais docentes; dos fundamentos pedagógicos e da organização curricular dos cursos de Licenciatura; por fim, processos avaliativos internos e externos.

9 Vide: http://www.anfope.org.br/anfope-repudia-a-aprovacao-pelo-cne-da-resolucao-que-define-asnovas-diretrizes-curriculares-para-formacao-inicial-de-professores-da-educacao-basica-e-institui-a-basenacional-comum-para-a-formacao-in/ Acesso 20 Mai.2020. 


\title{
O que os indicadores indicam?
}

\author{
O que dizes tem ressonância, \\ o que calas tem peso \\ de uma forma ou outra - político. \\ Wisława Szymborska
}

Especificamente na seção denominada "indicadores de aprendizagem e da formação de professores, apontando o desafio do baixo valor social da carreira do magistério no Brasil" o Parecer CNE/CP n 22/2019 apresenta a discussão sobre o desafio de mudar o baixo valor social da carreira do magistério no Brasil, e o atrela a avaliação do desempenho dos estudantes, ao apresentar os resultados da Avaliação Nacional de Alfabetização (ANA) de 2016 e a relação destes resultados com a meta 7, do Plano Nacional de Educação, concluindo "nota-se a dificuldade de avanços significativos no país nesta modalidade". (BRASIL, 2019, p. 4).

Esperava-se que houvesse uma descrição do Sistema Avaliação da Educação Básica, o Saeb, criado pela Portaria MEC n 1.792, de 27 de dezembro de 1994, alterado em 1999, pela Portaria MEC no 839. Em 2005, a Portaria MEC nº 931 também alterou novamente o desenho do Saeb. A última alteração sofrida pelo Saeb ocorreu em 2013, com a publicação da Portaria MEC $n^{\circ}$ 482. "A mudança comportou a inserção da Avaliação Nacional da Alfabetização (ANA) entre as avaliações do Saeb, sem que se alterasse o caráter centralizado das avaliações realizadas pelo governo federal". (SANTOS e OUTROS, 2017, p. 14-15) Há uma ausência da descrição da organização e funcionamento de nosso sistema de ensino para a Educação Básica. Alguns dados são apresentados, sem a devida contextualização, o que fragiliza os indicadores, permitindo questionar: por que e como são usados? Apenas, para comprovação de hipóteses ou verdades já absolutizadas?

Nesta mesma seção, há a ampliação destes indicadores para o Ideb (Índice de Desenvolvimento da Educação Básica), verificado e projetado para o Brasil no $5^{\circ}$ e $9^{\circ}$ ano do Ensino Fundamental (EF) e no $3^{\circ}$ ano do Ensino Médio (EM), entre 2007 e 2017 para escolas estaduais e municipais. O Parecer anuncia que os resultados levam a pensar em dois aspectos: refere-se à incumbência de zelar pela aprendizagem dos estudantes, conforme inciso III do artigo 13 da LDB; e o segundo, refere-se à importância da qualificação do professor para o processo de aprendizagem escolar dos estudantes. Ao apontar este segundo aspecto, apresenta "vários estudos" da OCDE (Organização para a Cooperação e Desenvolvimento Econômico) que indicam que "a qualificação dos professores para a qualidade do ensino ministrado é o fator mais importante para explicar o desempenho dos estudantes" (BRASIL, 2019, p. 5). Anuncia-se assim, a aprendizagem como o foco destas Diretrizes. Todas as ações propostas têm a aprendizagem como objetivo primordial. E o cenário até aqui delineado no Parecer refere-se ao fracasso do 
sistema de ensino brasileiro, especificamente, creditando ao/a professor/a a responsabilidade por este fracasso. Afinal de contas, as pesquisas mostram que "a qualificação dos professores é o fator mais importante". A culpa é de quem? Se não há aprendizagem, alguém não ensinou, ou ensinou mal. Esta é a conclusão que o texto do Parecer induz.

Outro estudo citado, Gatti (2014), aponta diversos desafios que ainda esperam ações no campo da formação inicial do/a professor/a no Brasil. A partir deste estudo, apresenta a proporção de docentes sem formação superior compatível com quaisquer das disciplinas que lecionam nos Anos Finais do EF e EM, em 2018, em que usa como fonte, o Anuário Brasileiro da Educação Básica (2019) produzido por Todos pela Educação ${ }^{10} \mathrm{e}$ Fundação Santillana ${ }^{11}$.

Também apresenta a evolução dos indicadores de trajetória nos Cursos de Pedagogia e Licenciatura em Química, Matemática e Física de 2010 a 2016, retirado do Censo da Educação Superior de 2018, com taxas de desistência dos alunos ingressantes em 2010 de 49,0\%, 61,9\%, 62,2\% e 71,8\%, respectivamente. Ao apresentar estes dados, afirma que

analisando todos os cursos de graduação, além daqueles vinculados à formação de professores, a evolução dos indicadores da trajetória dos estudantes ingressantes em 2010, no fluxo de 2010 a 2016, por modalidade de ensino, as taxas de desistência são altas e muito similares, ou seja, dos cursos presenciais a taxa é de $55,6 \%$ (...) (BRASIL, 2019, p. 7-8)

A diferença entre as médias apresentadas no documento para o mesmo fluxo, de 2010 a 2016, em relação aos cursos de licenciatura identificados (Pedagogia, Química, Matemática e Física) e os demais cursos de graduação presenciais é de 5,6\%. Diferença significativa ou não? Qual o parâmetro a ser usado para essa análise? O Parecer mostra os números como um fato, sem interpretações possíveis. Pensando nas características específicas e profissionais do/a professor/a, compreendo que a diferença seja pequena. $\mathrm{O}$ Parecer não enfrenta nenhuma análise, apenas apresenta o número, como se ele, em si, já demonstrasse as necessidades do cenário. Reafirma-se aqui, o alto índice de desistência que temos na Educação Superior, também questionável, de acordo com a definição e

\footnotetext{
${ }^{10}$ De acordo com o site, "O Todos Pela Educação é uma organização da sociedade civil, sem fins lucrativos, plural, suprapartidária e independente - não recebe recursos públicos. Fundado em 6 setembro 2006. Disponível em: https://www.todospelaeducacao.org.br/pag/quem-somos/\#bloco67 Acesso: 27 de abril de 2020.

${ }^{11}$ De acordo com o site, a Fundação Santillana foi “criada em 1979, atua na Espanha e em cinco países da América Latina. No Brasil desde 2008, trabalha em parceria com organizações nacionais e internacionais no desenvolvimento de projetos e obras de referência nas temáticas educacionais e da cultura". Disponível em: https://fundacaosantillana.org.br/a-fundacao-santillana/ Acesso: 27 de abril de 2020.
} 
caracterização que usamos do significado da evasão (COIMBRA, SILVA, COSTA, 2020).

Neste momento, ao apresentar os dados e diferenças entre os cursos presenciais e a distância, o Parecer recupera o $§ 3^{\circ}$ do artigo 62 da LDB (Lei n ${ }^{\circ}$ 9.394/96) que diz: "a formação inicial de profissionais de magistério dará preferência ao ensino presencial, subsidiariamente fazendo uso de recursos e tecnologias de educação a distância". Entretanto, os dados apresentados caminham na direção oposta da LDB. O Parecer anuncia, mesmo que timidamente,

Notadamente, isso implica que o Ministério da Educação precisa não somente zelar pelo que está posto na LDB quanto ao dispositivo acima, como supervisionar e monitorar a qualidade da oferta para as duas modalidades, para assegurar que este futuro professor tenha efetivamente desenvolvido as competências previstas neste Parecer, o que deve incluir também um sistema de avaliação de egressos. (BRASIL, 2019, p. 8)

Anuncia, mas não desenvolve a ideia do que seria ou como seria esta ação do MEC, especialmente no que se refere ao sistema de avaliação de egressos. A crítica é leve, mas chama o MEC para sua responsabilidade de zelar pelo cumprimento da LDB, Lei de Diretrizes e Bases da Educação Nacional, especificamente ao número de cursos de formação inicial de professores/as para a Educação Básica na modalidade a distância.

O Parecer também utiliza um estudo da Varkey Foundation ${ }^{12}$, no qual o Brasil ficou na última posição, ou seja, o país que menos valoriza seus professores/as. $\mathrm{O}$ contexto do uso desta pesquisa não é esclarecido no Parecer, bem como a fonte de sua realização, de quais países trata. Fica difícil compreender em qual situação de valorização social esta pesquisa foi realizada. A ausência de descrição e detalhamento, impedem a compreensão de sua contribuição no cenário.

Para consolidar a ideia da valorização docente, cita estudos realizados pelo BID Banco Interamericano de Desenvolvimento e OCDE - Organização para a Cooperação e Desenvolvimento Econômico, divulgados em 2018, que revelam que "a maioria dos jovens não deseja se tornar professor".

Além da questão financeira, a pesquisa do BID aponta as condições de trabalho como razão do desinteresse dos jovens pela docência. O estudo da OCDE vai na mesma direção, é o que se pode concluir a partir dos

\footnotetext{
${ }^{12}$ De acordo com o site da Fundação: "Nós somos a Fundação Varkey. Acreditamos em uma educação de qualidade para todas as crianças. É por isso que, juntamente com nossos parceiros, trabalhamos para desenvolver a capacidade e o status dos professores, a fim de garantir que a qualidade do ensino seja aprimorada e que os resultados melhorem." Disponível em: https://www.varkeyfoundation.org/pt/quemn\%C3\%B3s-somos/sobre-a-funda\%C3\%A7\%C3\%A3o-varkey/ Acesso em 27 de abril de 2020.
} 
dados do relatório "Políticas Eficientes para Professores". (BRASIL, 2019 , p. 8)

São citadas várias pesquisas, especialmente de organismos internacionais, com dados genéricos e pontuais sobre determinado aspecto da Valorização docente, entretanto, estas não são analisadas em sua intencionalidade e proposições. Há, claramente, por parte do Parecer, uma opção em buscar parceiros ancorados em organizações do terceiro setor, desprezando a produção acadêmica nacional sobre o tema. Claramente o diálogo científico não foi travado com as universidades públicas, onde concentram-se os Programas de Mestrado e Doutorado que produzem pesquisas sobre a educação, a formação de professores/as e temas afins. Organizações empresariais, como Todos pela Educação (TPE), e outras novas e até então desconhecidas no campo educacional, algumas estrangeiras, são citadas e referenciadas no Parecer, tais como, Fundação Santillana, Varkey Foundation, Instituto Canoa e Movimento Profissão Docente.

Ainda ao final desta seção, são apresentadas as metas 17 e 18 do Plano Nacional de Educação (PNE) sobre a equivalência salarial, plano de carreira, Lei do Piso e Fundeb, como fortes instrumentos na busca da valorização social do professor. $\mathrm{O}$ documento ocupa 19 parágrafos para o debate sobre o valor social do/a professor/a, entretanto, esta seção não aparece no texto da Resolução, o que existia na anterior. O PNE é uma das fortes ausências percebida na comparação entre as duas últimas Resolução: 2015 e 2019.

Em síntese, o que os indicadores apontam? Indicam que os parceiros de diálogo são organismos criados, pelo que Freitas (2018) denomina de "reformadores da educação", instituições novas, fortemente vinculadas ao pensamento empresarial, neoliberal, e que não têm história na formação de professores/as no Brasil. Em contrapartida, temos a invisibilização das Universidades públicas brasileiras e das pesquisas que estas realizam no campo educacional, especificamente, sobre a formação de professores. Causa estranhamento, em documento desta natureza, o fato de não haver qualquer referência de pesquisa, dado ou indicador oriundo das Universidades.

\section{A supremacia de dados e referências internacionais}

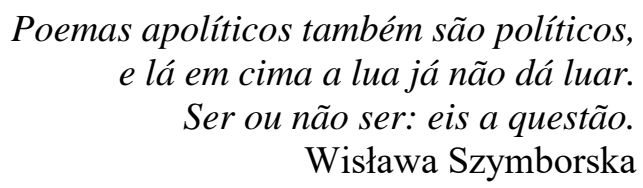

Apesar de já ter apresentado várias referências de estudos internacionais, o Parecer apresenta uma sessão com este título: Referenciais e diretrizes internacionais. Nesta seção, defende que: 
no que concerne à melhoria dos resultados educacionais, principalmente quanto ao desempenho escolar dos estudantes, vale salientar que os referenciais docentes são de fundamental importância para se compreender esta problemática. Como evidências dessa asserção, apresentamos brevemente o resultado de experiências internacionais que podem nos inspirar na construção de diretrizes curriculares para a formação de professores no Brasil (...) (BRASIL, 2019 , p. 9 grifo nosso)

Nesta perspectiva, mais uma vez, a ideia da aprendizagem aparece como foco iniciando apenas citando o livro produzido pela Unesco intitulado "Professores do Brasil: novos cenários de formação", sob a organização de Gatti (2014), dentre outras autoras, para dizer que a formação inicial de professores "é um grande desafio a ser vencido" e por isso as experiências internacionais devem ser buscadas.

Neste momento, o Parecer apresenta, sem referência sobre sua origem ou fonte, uma série de argumentos, tais como:

a) os referenciais para a formação docente consistem em descrever o que os professores devem saber e ser capazes de fazer;

b) os descritores e diretrizes tem 3 dimensões: conhecimento sobre como os alunos aprendem, os saberes específicos das áreas do conhecimento e o conhecimento pedagógico;

c) a experiência internacional mostra a importância de se trabalhar com fundamento em evidências científicas de como os estudantes aprendem;

d) ao grau de detalhamento na construção dos referenciais depende de cada experiência de cada país;

e) os referenciais podem estar alinhados aos mecanismos de avaliação e acreditação dos cursos de formação inicial e avaliações dos estudantes ou recém-graduados;

f) os referenciais podem estar articulados a mecanismos de certificação ou registro para controlar o ingresso na carreira docente.

Estas afirmações são assertivas e sem qualquer referência ao que atestam. De quais países? Quais são as referências? Para qual fim? Para qual projeto de sociedade? Há a percepção de que este Parecer tenha sido produzido para determinado fim, ou seja, para extrair das experiências internacionais citadas, aquilo que já havia intencionado como hipótese e objetivo. A materialização disso são as letras $e$ e $f$, que tratam dos mecanismos de avaliação, acreditação e certificação. Nos últimos anos, percebe-se, dentro do MEC, uma forte intenção em realizar a certificação docente e esta tese aparece aqui como uma experiência possível e já realizada internacionalmente. Em qual país? Em que condições? 
Sabemos que a formação inicial de professores/as, a depender do país de análise, é marcada por diferenças essenciais e existenciais. Como buscar apenas aquele país ou aquela experiência que queremos?

Para concluir a incoerência desta seção do documento, cita uma pesquisa do Instituto Canoa ${ }^{13}$, contratada pelo movimento Profissão Docente ${ }^{14}$, que

analisou as diretrizes nacionais de regulamentação das licenciaturas em 10 países, todos selecionados com base na qualidade dos seus sistemas de educação ou na evolução dos indicadores de desempenho de acordo com os resultados do PISA. São eles: Austrália, Canadá (British Columbia), Chile, EUA (Califórnia), Finlândia, Inglaterra, Nova Zelândia, Peru, Portugal e Singapura. (BRASIL, 2019, p. 10)

Neste caso, o Parecer apresenta os objetivos da pesquisa e as principais conclusões desta. Há uma diversidade de temas nestas conclusões e muitas delas estão reproduzidas no texto da Resolução. A referência a estes dois organismos - Instituto Canoa e Movimento Profissão Docente, - assim como as outras fundações citadas, evidenciam uma atitude recente do Conselho Nacional de Educação de estabelecer parcerias com organizações demasiadamente recentes no campo da educação. O Movimento Profissão Docente data de 2019, especialmente criado e posteriormente independentizado no TPE. Assim, parece ser uma opção a ausência da história da educação brasileira que poderia contextualizar a trajetória vivida até aqui. A sensação que fica é a de que não temos história. Não houve a definição de um perfil de formação de professores e professoras no Brasil. A história inicia-se a partir da aprovação da BNCC e da avalanche de mudanças que ela carrega consigo. Onde estão Anfope, Anped, Anpae, Fórum em Defesa da Escola Pública? Desaparecem do cenário nos argumentos e teses deste Parecer. Nenhuma referência é feita aos modelos anteriores, ao movimento histórico que contextualiza como chegamos no tempo presente. Consideramos este, talvez, mais um dos grandes prejuízos deste documento.

Para finalizar esta seção, há um parágrafo sobre o Pibid (Programa Institucional de Bolsa de Iniciação à Docência), citando-o como "uma das experiências mais exitosas

\footnotetext{
${ }^{13}$ De acordo com o site "O Instituto Canoa é uma organização sem fins lucrativos criada com a missão de fomentar a formação de professores de excelência no país.” Disponível em: http://institutocanoa.com.br/ Acesso em: 27 de abril de 2020.

${ }^{14}$ De acordo com o site, "junto a importantes organizações do terceiro setor educacional, o Todos pela Educação estruturou uma iniciativa inédita no Brasil dedicada unicamente à valorização e profissionalização da carreira docente: o Profissão Professor. A partir de 2019, esse novo movimento de advocacy, focado em melhorar a qualidade das políticas docentes no País, ganhou independência organizacional, tendo tudo para contribuir com o avanço de mudanças estruturantes em âmbito nacional presentes na agenda do Educação Já!" Disponível em: https://www.todospelaeducacao.org.br/pag/iniciativa-profissao-professor Acesso em 27 de abril de 2020.
} 
que contribui para a formação inicial docente" que "favorece também a articulação das políticas das redes de ensino, bem como fortalece o regime de colaboração entre as instituições de ensino superior formadoras e as secretarias de educação nas esferas". Fora de lugar e de forma reducionista, o Pibid aparece em um parágrafo, na seção denominada "Referenciais e diretrizes internacionais". Um Programa de mais de uma década de existência no país, com revelada importância é tratado de forma superficial e coadjuvante neste Parecer. E o Programa de Residência Pedagógica? Um Programa mais recente, mas também existente como política pública brasileira recente. Evidencia-se, assim, uma ausência, no Parecer, de dados de nossa realidade. A fonte destas avaliações sobre o Pibid não é identificada e apresenta a BNCC como "outra experiência que merece comentários" que serão tratados na sequência. Uma busca instantânea, realizada no banco de periódicos da Capes, apresenta 674 artigos sobre o Pibid. Sem filtro e sem profundidade. Um Programa que tem mais de 10 (dez) anos de história. Somente esta reflexão no Parecer que dá subsídios para a formação de professores/as no Brasil. Causa estranhamento. Ao contrário, a BNCC, com apenas 2 anos de sua aprovação, conquista uma seção, e o lugar central na proposição. Quais valores? Qual importância e significado damos para ambos? Não há opções neutras no campo da educação. Delineia-se assim, a pergunta da Alice: aonde se quer chegar...

Infelizmente, anuncia-se um lugar de chegada anacrônico, separado de nosso tempo histórico, de nossas necessidades, de nossas conquistas no campo da formação de professores/as.

\title{
O espelhamento da BNCC- Educação Básica com a BNC-Formação
}

\author{
Somos os filhos da época, \\ e a época é política. \\ Wisława Szymborska
}

Ao iniciar a seção sobre a BNCC, afirma-se que "no caso brasileiro, a construção de referenciais para a formação docente precisa dialogar com as dez competências gerais da BNCC, bem como com as aprendizagens essenciais que a BNCC garante aos estudantes da Educação Básica". Há, desta forma, uma analogia entre as duas Resoluções, a que institui a BNCC (2017) e a que aprova a BNC da Formação (2019), impetrando a ideia de que uma não vive sem a outra, uma é complementar à outra e para argumentar sobre isso são utilizados:

a) a conformidade legal da BNCC e portanto, também desta Resolução com o art. 205 da Constituição Federal; com o art. $2^{\circ}$ da LDB, com as Leis $n^{\circ}$ 10.639/03, e n ${ }^{\circ} 11.645 / 08$, com a Declaração Universal dos Direitos Humanos (1948) no Artigo no 26, o Pacto Internacional sobre Direitos Econômicos, 
Sociais e Culturais (1966) no Artigo n 13 , e a Convenção sobre os Direitos da Criança (1989);

b) o atendimento aos desafios do século XXI, "ao mundo VUCA (Volatility, Uncertainty, Complexity e Ambiguity, em português: volatilidade, incerteza, complexidade e ambiguidade, respectivamente)"; e

c) o alinhamento aos avanços das tecnologias de comunicação e informação.

Estes argumentos são anunciados como medidas de cumprimento legais e, ao mesmo tempo, atualização com as demandas de nosso tempo. Mas, não são. Daqui decorre as características principais deste modelo anacrônico.

Nenhuma referência é apresentada para a discussão do quanto a BNCC, as competências e a formação devam estar interligadas, em sintonia, buscando a mesma formação: "a necessidade de desenvolvimento de conhecimentos, habilidades, atitudes e valores que possibilitem aos estudantes compreender e construir relações com os outros e consigo mesmo de modo confiante, criativo, resiliente e empático, para citar apenas alguns exemplos." Quais referências para o mundo VUCA? De onde e quais referenciais, no Brasil, aponta-se para esse caminho? Inovar, atualizar, trazer as novas tecnologias de comunicação e informação, são as demandas para a formação de professores/as no Brasil? Há um anacronismo das discussões nacionais com estas usadas no Parecer, tanto os organismos do terceiro setor, quanto a ausência de informações sobre este mundo VUCA, a ser alcançado.

Ousamos dizer que os "reformadores da educação", que tem suas origens em cursos de administração, direção e gestão de empresas, em sua maioria, transportam de seu mundo para o nosso, as mesmas definições e conceitos. O delineamento de uma lógica empresarial na formação de professores/as está aqui claramente explicitado. Um vocabulário corporativo espelhando a ideia de formação para as competências do mercado. Além dessa compreensão, afirma que

Espera-se, de um bom profissional da área, que ele esteja preparado para articular estratégias e conhecimentos que permitam também desenvolver essas competências sociemocionais em seus estudantes, considerando as especificidades de cada um e estimulando-os em direção ao máximo desenvolvimento possível. Ao longo da formação no nível superior, os licenciandos devem construir, portanto, uma base robusta de conhecimento profissional que lhes permita agir sobre a realidade, apoiar as aprendizagens dos estudantes com os quais estão trabalhando, e que lhes ofereça bases substanciais para continuarem aprendendo ao longo de sua carreira. (BRASIL, 2019, p. 12-13)

Uma linguagem empresarial parece assumir a finalidade do perfil do/a egresso/a na formação inicial de professor/a no Brasil: "estar preparado" para "articular 
estratégias". Parece que há, uma redução da função do ser professor/a, a partir deste perfil anunciado. Somos estrategistas para formar estrategistas? A ideia que fica desta seção é esta. Esta é a exigência do mundo VUCA? A BNCC precisa de um "aplicador" de conteúdos, ops! Não podemos falar conteúdos, são objetos de conhecimento, pois este é o nome utilizado na BNCC. Neste caso, sinônimos, em nossa interpretação. Um/a professor/a competente que forma um/uma estudante competente.

Apesar de anunciar a desvalorização social do professor/a no Brasil, no momento de defender as competências, individualiza como função do/a formador/a. Vistamos as capas de mulher maravilhas e vamos conseguir o "máximo de desenvolvimento possível", a qualquer custo, em qualquer cenário, sob quaisquer condições. Um trabalho para superheroínas. Afinal de contas, a culpa é sua!

Os princípios e as competências: como articular?

Oh, querida que questão mal parida. A questão política. Não precisas nem ser gente para teres importância política.

Wisława Szymborska

Ao anunciar os princípios da política de formação de professores, o Parecer reconhece como relevantes, a partir da BNCC:

(a) formação docente para todas as etapas e modalidades da Educação Básica como compromisso de Estado, que assegure o direito das crianças, dos jovens e adultos a uma educação de qualidade, mediante a equiparação de oportunidades que considere a necessidade de todos e de cada um dos estudantes;

(b) valorização da profissão docente, que inclui o reconhecimento e o fortalecimento dos saberes e das práticas específicas da profissão;

(c) colaboração constante entre os entes federados para a consecução dos objetivos de uma política nacional de formação de professores para a Educação Básica;

(d) garantia de padrões de qualidade dos cursos de formação de docentes ofertados pelas instituições formadoras nas modalidades presencial e a distância;

(e) articulação entre a teoria e a prática no processo de formação docente, fundada nos conhecimentos científicos e didáticos, que contemple a indissociabilidade entre o ensino, a pesquisa e a extensão, visando garantir o desenvolvimento dos estudantes;

(f) equidade no acesso à formação inicial e continuada, contribuindo para a redução das desigualdades sociais, regionais e locais;

(g) articulação entre a formação inicial e a formação continuada;

(h) formação continuada entendida como componente essencial da profissionalização docente, devendo integrar-se ao cotidiano da 
instituição educativa e considerar os diferentes saberes e a experiência docente, bem como o projeto pedagógico da instituição de Educação Básica na qual atua o docente;

(i) compreensão dos docentes como agentes formativos de conhecimento e cultura e, como tal, da necessidade de seu acesso permanente a conhecimentos, informações, vivência e atualização cultural;

(j) liberdade de aprender, ensinar, pesquisar e divulgar a cultura, o pensamento, a arte, o saber e o pluralismo de ideias e de concepções pedagógicas. (BRASIL, 2019, p. 13, grifo nosso)

Tais princípios não apresentam declaração de origem e nem mesmo referências de onde foram retirados. São estes. Conseguimos identificar alguns destes reescritos alterando seu sentido - a partir da Resolução de 2015, o modelo de resistência, mas nenhuma menção é feita neste sentido. A impressão é de que em alguns casos, perdeu-se o sentido, ou melhor, este esvaziou-se. Um exemplo disso, refere-se a letra $b$ em que a simplificação da reescrita, prejudicou seu conteúdo, alterando-o. Assim estava escrito na Resolução de 2015:

II - a formação dos profissionais do magistério (formadores e estudantes) como compromisso com projeto social, político e ético que contribua para a consolidação de uma nação soberana, democrática, justa, inclusiva e que promova a emancipação dos indivíduos e grupos sociais, atenta ao reconhecimento e à valorização da diversidade e, portanto, contrária a toda forma de discriminação; (BRASIL, 2015)

Ao transpor o princípio ele é esvaziado de sentido, perde-se a ideia principal de assumir o papel de transformação da educação tanto para formadores/as quanto para estudantes, característica fundamental no modelo de resistência. Ao eliminar trechos, compreende-se que estes princípios assumem, novamente, a intenção já anunciada deste modelo de uma concepção neotecnicista da formação de professores/as no Brasil, em uma dimensão explicitamente instrumental da profissão e, portanto, da formação.

Ressaltamos a ideia do direito a educação, da valorização profissional, da articulação entre a teoria e a prática, e entre formação inicial e continuada, e, por fim, os dois últimos princípios que definem uma concepção de docente, como agentes formativos de conhecimento de cultura, e a liberdade como um princípio para a formação, presentes no modelo de resistência, da Resolução 2015. A percepção que temos é de que até aqui, o Parecer traz referências distantes e distintas destes princípios. Há uma ruptura em termos de concepção do que foi anunciado até 2015 e o que os princípios e proposições da Resolução 2019 anunciam, como temos apresentado desde o início deste artigo.

Além dos princípios anteriores, há na seção seguinte, 14 (catorze) princípios da organização curricular nos cursos de formação de professores. São considerados princípios norteadores "em consonância com as aprendizagens prescritas na BNCC". 
UM MODELO ANACRÔNICO PARA OS CURSOS DE LICENCIATURA NO BRASIL:

Uma análise do Parecer CNE/CP no 22/2019

Qual a relação entre estes 24 princípios, quais articulações possíveis? São apenas enumerados. Listados. Não há a clareza e coerência entre os princípios e os meios expressos.

Na mesma lógica da BNCC, o Parecer retrata as competências profissionais docentes. "Essas competências gerais, bem como as específicas para a docência, e as habilidades a elas correspondentes, compõem a Base Nacional Comum para a Formação Inicial de Professores da Educação Básica (BNC-Formação).” Estas competências, são compostas, segundo o parecer, por três dimensões: conhecimento profissional, prática profissional e engajamento profissional.

O conhecimento profissional pressupõe uma formação específica e permite a atuação docente autônoma. Retrata a aquisição de saberes que dão significado e sentido à prática profissional realizada em âmbito escolar. Os conhecimentos da área, da etapa e do componente curricular estão no âmago da competência.

Tão imprescindível quanto abordar os saberes é valorizar o conhecimento pedagógico do conteúdo, ou seja, a forma como esses são trabalhados em situação de aula, na prática profissional: sequências didáticas, progressão e complexidade de conhecimentos abordados, experiências práticas, planejamento reverso, metodologias inovadoras e aprendizagem ativa, para citar alguns exemplos, e vivenciados pelo licenciando.

Trata-se, desse modo, de um compromisso moral e ético do professor para com os estudantes, seus pares, os gestores, a comunidade escolar e com os demais atores do sistema educacional. O engajamento profissional pressupõe o compromisso consigo mesmo (desenvolvimento pessoal e profissional), o compromisso com o outro (aprendizagem e pleno desenvolvimento do estudante) e o compromisso com os outros (interação com colegas, atores educacionais, comunidade e sociedade). (BRASIL, 2019, p. 15-16)

Assim, o Parecer apresenta 10 competências gerais docentes BNC-Formação, e cada dimensão apresenta um conjunto de competências específicas. 
Desenho 1: Verbos das 10 competências

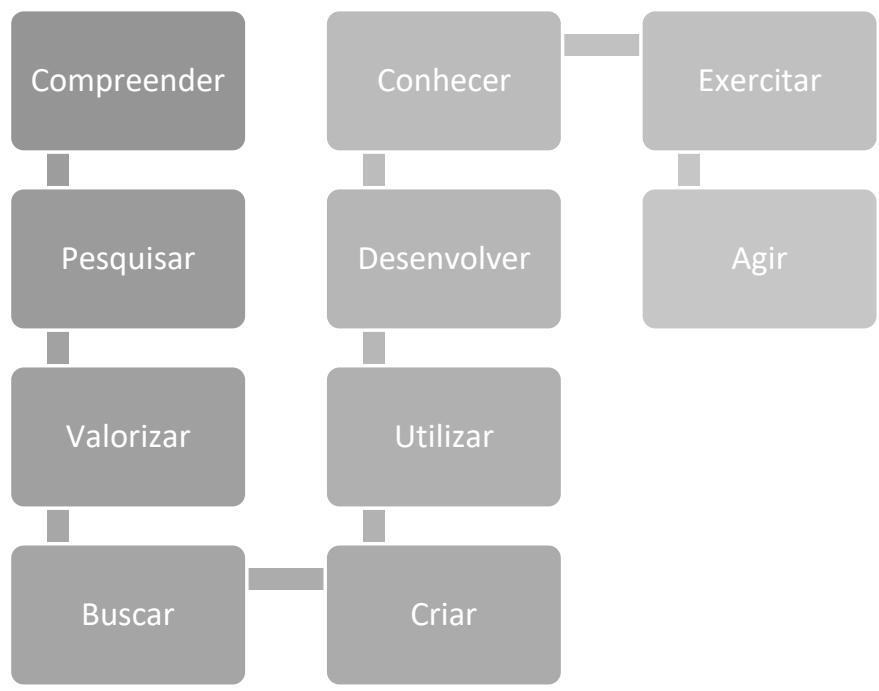

Para o conhecimento profissional, das 4 competências apresentadas, são listadas 21 habilidades. Para a prática profissional, das 4 competências apresentadas, são listadas 21 habilidades. Para o engajamento profissional, das 4 competências apresentadas, são listadas 19 habilidades. Vamos somar? Em um Curso de 3200 horas, temos 24 princípios, 22 competências e 61 habilidades para a formação de professores/as, além de temáticas também apresentadas.

Desenho 2: Dimensões, competências específicas e habilidades

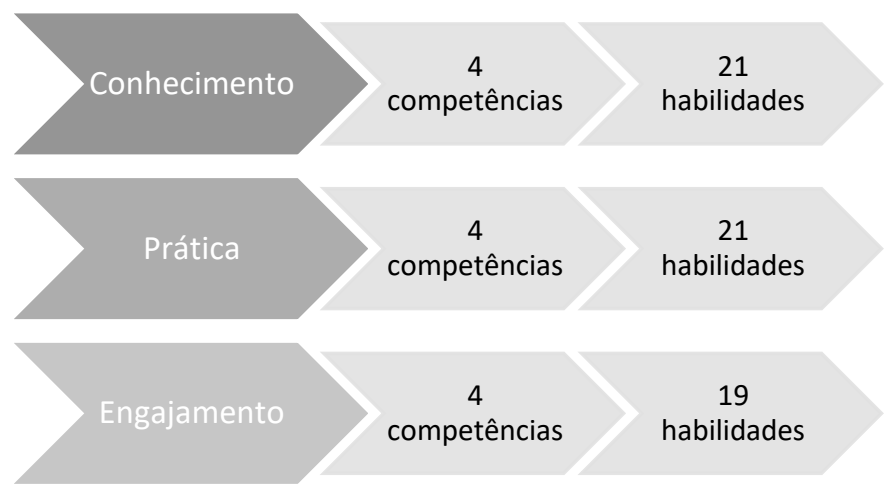

Estas 10 (dez) competências da BNC-Formação aproximam-se, sobremaneira, das 10 (dez) competências da BNCC- Educação Básica. As mudanças são para os sujeitos a que se referem. A ideia do espelhamento foi cumprida com êxito. O que o/estudante tem que fazer lá na Educação Básica é o que o/a estudante/licenciando/a vai aprender no curso de formação. A compreensão é de que seja, de fato, um espelho estas, daquelas.

Diferencia-se, portanto, em termos de estrutura das Diretrizes, os princípios, os fundamentos, as competências gerais e específicas e, ainda, as habilidades apontadas do 
conhecimento e temáticas que serão tratadas. Não percebemos a articulação necessária entre os princípios, as competências, as dimensões e suas habilidades, bem como os conhecimentos e temáticas que estão no documento.

Depois de apresentadas as competências a habilidades - representadas em tabelas -, o item seguinte denomina-se: fundamentos pedagógicos. Neste momento, há uma pergunta essencial: os fundamentos não deveriam sustentar a BCN-Formação? Quais são os fundamentos para as competências anunciadas? Ao ler a listagem dos 9 (nove) fundamentos, evidencia-se a compreensão de um Parecer em uma concepção neotecnicista. Os "fundamento pedagógicos" listados propõem instrumentalizar o "futuro professor/a" com domínio da leitura e produção de textos, no compromisso com metodologias inovadoras, com o processo de construção do conhecimento, com o emprego pedagógico das inovações e linguagens escolares, da avaliação como parte integrante do processo de formação, da apropriação do conhecimento relativos à gestão educacional, reconhecimento da escola como espaço privilegiado da formação do/a professor/a, compromisso com a educação integral dos professores em formação e por fim, nas decisões pedagógicas com base em evidências. Somamos 24 princípios, 22 competências, 61 habilidades e 9 fundamentos, em 3200 horas. Qual a relação entre esta lista "de coisas"? Qual caminho quer seguir? Como articular? Não há pistas sobre isso.

Voltamos a ideia inicial, o conceito de prática anunciado neste documento está presente de diversas formas, inclusive quando estes conceitos não interagem em um projeto de formação de professores/as. A prática como praticismo. O fazer pelo fazer. Parece que a quantidade prevalece à qualidade. Abunda certa confusão, que parece-nos intencional, e evidencia-se a falta de articulação e sentido. Qual o caminho?

Nosso objetivo não é, neste momento, fazer uma análise do conteúdo dos princípios e meios do Parecer, mas apenas apresentar uma visão inicial, da imagem, da proposição, do entendimento de qual projeto de formação está em jogo. A análise do conteúdo deste Parecer exigirá outros tantos artigos para nossa compreensão e análise. A ideia de instrumentalização da formação, de formar um/a professor/a "aplicador/a da BNNC" é o nosso projeto de formação de professores/as para a nação? 


\title{
A subversão como proposição
}

\author{
Basta ser petróleo, ração, \\ qualquer derivado, ou até \\ uma mesa de conferência cuja forma \\ vem sendo discutida meses a fio. \\ Wisława Szymborska
}

Em todos os aspectos analisados no Parecer 22/2019, desde os indicadores apresentados, a supremacia de dados e referenciais internacionais, o espelhamento da BNCC-Educação Básica na BNC-Formação, evidencia-se certa confusão intencional de quais são os princípios, os fundamentos, as competências e as habilidades em foco. Materializam um projeto de formação de professores/as no Brasil, sabem como diria Alice, onde querem chegar. Um modelo, de fato, anacrônico, não serve ao nosso tempo e a nossa história, não serve a um projeto progressista de educação, que considera a profissão de professor/a, que considera os saberes que constituem a prática educativa, que considera a função social da escola, que busca uma sociedade justa, democrática, inclusiva e solidária.

A frase de Mello (2000), como epígrafe de seu artigo "Formação inicial de professores para a educação básica: uma (re)visão radical", em que cita Shaw: "Quem sabe faz, quem não sabe ensina.”, parece ser a premissa deste modelo anacrônico. Vamos ensinar a fazer porque assim, estaremos ensinando a ensinar. Compreensão da prática pela prática. O saber fazer assume preponderância na compreensão e definição de docência, por este ideário instrumental, neotecnicista, fortemente apresentado neste Parecer e, por consequência, na Resolução.

Desta forma, em uma análise inicial, o Parecer apresenta dados difusos, incoerentes, incompatíveis, na contramão de um projeto de formação, profissionalidade e valorização docente que vinha sendo construído no Brasil, desde final da década de 1970. A Resolução 02/2015 materializou um projeto construído coletivamente com entidades existentes desde as décadas de 1980 e 1990 no Brasil, tais como Anfope, Anpae e Fóruns criados desde a discussão e aprovação da LDB (Lei no 9394/96), bem como outros documentos produzidos para a Educação Básica ao longo de nossa história.

A compreensão da politicidade e historicidade na educação, são categorias chave para a nossa análise de conjuntura e de compreensão do modelo e do cenário de nossa sociedade. Por isso recorremos ao poema de Wisława Szymborska, "Filhos da época", pois "somos os filhos da época, e a época é política". Há que se compreender que a negação destas categorias, em um projeto de formação de professores/as não se dá ao acaso, mas com intenções claras de formar um sujeito esvaziado de história, de seu tempo 
cultural e de sua politicidade, na contramão de um projeto de nação em uma perspectiva de transformação das pessoas e da sociedade.

Reafirmamos assim, que o modelo anacrônico, numa sociedade complexa e mutante como a nossa, impõe um ideário dissonante ao afirmar que "o bom professor" ou a "boa professora" é aquele/a que sabe fazer. A quantidade de competências envolvidas neste modelo de formação, traduzem uma compreensão de que "o profissional competente é aquele que faz". Assim, o modelo anacrônico não possibilita que convivamos, não possibilita que esta sociedade o instaure como modelo, pois foge a seu tempo. A proposição que fazemos é a sua subversão total. Não aceitamos este reducionismo proposto pelo Parecer 22/2019 e pela Resolução CNE/CP n 2/2019 para a formação de professores/as no Brasil. Lutaremos e resistiremos em uma convocação ampla, das Universidades públicas, escolas públicas, professores e professoras da Educação Básica e da Educação Superior, profissionais da educação, mães e pais de estudantes, estudantes dos cursos de licenciatura, a enfrentar mais esta luta necessária à educação brasileira.

\section{Referências}

ANFOPE, FORUMDIR, ANPED et al. Contra a descaracterização da formação de professores. Nota das Entidades Nacionais em defesa da Res. 02 /2015. Datada de 9 de outubro de 2019. Disponível em http://www.anfope.org.br/wp-content/uploads/2019/10/ Nota-entidades-forma\%C3\%A7\%C3\%A3o-atual-v.14out.pdf Acesso em: 06 Abril 2020.

ANFOPE. Boletim da ANFOPE. Campinas, setembro, 1998. Disponível em: http://www.lite.fe.unicamp.br/grupos/formac/indice/boletim8.html Acesso em: 06 Abril 2020.

ANFOPE. Boletim da ANFOPE. 2018. Disponível em http://www.anfope.org.br/wpcontent/uploads/2018/10/BOLETIM-ANFOPE-n1_2018.pdf Acesso em: 6 Abril 2020.

BRASIL. MEC. CNE. Conselho Pleno. Resolução CNE/CES nº 2, de 20 de dezembro de 2019. Define as Diretrizes Curriculares Nacionais para a Formação Inicial de Professores para a Educação Básica e institui a Base Nacional Comum para a Formação Inicial de Professores da Educação Básica (BNC-Formação). Diário Oficial da União, Brasília, 20 fev. 2019. Disponível em: http://portal.mec.gov.br/docman/dezembro-2019-pdf/135951rcp002-19/file. Acesso em: 06 Abril de 2020.

BRASIL. MEC. CNE. Conselho Pleno. Parecer CNE/CES n ${ }^{\circ} 22$, de 07 de novembro de 2019. Diário Oficial da União, Brasília, 2019. Disponível em: http://portal.mec.gov.br/ index.php?option=com_docman\&view=download\&alias=133091-pcp022-19-3\&catego ry slug=dezembro-2019-pdf\&Itemid=30192. Acesso em: 06 Abril 2020. 
BRASIL. MEC. CNE. Conselho Pleno. Resolução CNE/CES nº 2, de 22 de dezembro de 2017. Diário Oficial da União, Brasília, 2017. Disponível em: http://portal.mec.gov.br/ index.php?option=com docman\&view=download \&alias=79631-rcp002-17-pdf\&catego ry_slug=dezembro-2017-pdf\&Itemid=30192. Acesso em: 29 maio 2019.

BRASIL. MEC. CNE. Conselho Pleno. Resolução CNE/CP Nº 2 de $1^{\circ}$ de julho de 2015. Define as Diretrizes Curriculares Nacionais para a formação inicial em nível superior (cursos de licenciatura, cursos de formação pedagógica para graduados e cursos de segunda licenciatura) e para a formação continuada. Diário Oficial da União, Brasília, DF, 2 jul. 2015. Seção 1, p. 8-12. Disponível em: http://portal.mec.gov.br/docman/ agosto-2017-pdf/70431-res-cne-cp-002-03072015-pdf/file. Acesso em: 11 dez. 2015.

BRASIL. MEC. CNE. Câmara de Educação Superior. Resolução CNE/CES nº 2, de 18 de junho de 2007. Dispõe sobre carga horária mínima e procedimentos relativos à integralização e duração dos cursos de graduação, bacharelados, na modalidade presencial. Diário Oficial da União, Brasília, 19 jun. 2007. Seção 1. P. 6. Disponível em: http://portal.mec.gov.br/cne/arquivos/pdf/2007/ rces002_07.pdf. Acesso em: 04 jul. 2019.

BRASIL. MEC. CNE. Conselho Pleno. Resolução CNE/CP No 1, de 18 de fevereiro de 2002. Institui Diretrizes Curriculares Nacionais para a Formação de Professores da Educação Básica, em nível superior, curso de licenciatura, de graduação plena. Diário Oficial da União, Brasília, DF, 9 abr. 2002a. Seção 1, p. 31. Seção 1, p. 31. Disponível em: http://portal.mec.gov.br/cne/arquivos/pdf/rcp01_02.pdf. Acesso em: 12 maio 2002.

BRASIL. MEC. CNE. Conselho Pleno. Resolução CNE/CP No 2, de 19 de fevereiro de 2002. Institui a duração e a carga horária dos cursos de licenciatura, de graduação plena, de formação de professores da Educação Básica em nível superior. Diário Oficial da União, Brasília, DF, 9 abr. 2002b. Seção 1. P. 9. Disponível em: http://portal.mec.gov.br/ cne/arquivos/pdf/ CP022002.pdf. Acesso em: 12 jun. 2012.

BRZEZINSKI, Iria. Pedagogia, Pedagogos e Formação de Professores. Campinas, SP: Papirus, 1996.

COIMBRA, Camila Lima. Os Modelos de Formação de Professores/as da Educação Básica: quem formamos? Educ. Real., Porto Alegre, v. 45, n. 1, e91731, 2020. Disponível em https://www.scielo.br/scielo.php?script=sci_arttext\&pid=S2175-62362020000100 604. Acesso em 06 Abril 2020.

COIMBRA, C., SILVA, L. B.; COSTA, N. C. D. A evasão na Educação Superior: definições e trajetórias. 2020. No prelo.

FREITAS, Luiz Carlos de. A reforma empresarial da educação: nova direita, velhas ideias. São Paulo: Expressão Popular, 2018.

MELLO, Guiomar Namo de. Formação inicial de professores para a educação básica: uma (re)visão radical. São Paulo em perspectiva, 14(1), 2000. 
UM MODELO ANACRÔNICO PARA OS CURSOS DE LICENCIATURA NO BRASIL:

Uma análise do Parecer CNE/CP no 22/2019

SANTOS, Alexandre André dos. et. al. (Orgs.) Sistema Nacional de Avaliação da Educação Básica (Sinaeb). Proposta para atender ao disposto no Plano Nacional de Educação. Brasília, DF: Instituto Nacional de Estudos e Pesquisas Educacionais Anísio Teixeira, 2017.

SILVA, Andréa Villela Mafra da. Neotecnicismo - a Retomada do Tecnicismo em Novas Bases. Rev. Ens. Educ. Cienc. Human., Londrina, v. 19, n.1, p. 10-16, 2018.

SZYMBORSKA, Wisława. Filhos da época. In: SZYMBORSKA, W. Poemas. Tradução: Regina Przybycien. São Paulo, Companhia das Letras, 2011.

*Camila Lima Coimbra é Professora do Núcleo de Didática, da Faculdade de Educação, da Universidade Federal de Uberlândia. Pesquisadora do Grupo de Pesquisa Observatório de Políticas Públicas - OPP/UFU. Pesquisadora do Grupo de Pesquisa Currículo: questões atuais da PUC/SP.

E-mail: camilima8@gmail.com

https://orcid.org/0000-0002-7755-9473 